\title{
Using Systems Thinking to Teach ERP Project Implementation (TERPPJ)
}

\author{
Carin Chuang and Kuan-Chou Chen
}

\begin{abstract}
This paper presents a system model of ERP implementation based on nowadays case study and literatures. The relationships in the model are designed to be simple and functional and do not necessarily represent any particular business environments. It is meant to be a generic ERP implementation conceptual model with implications for MIS/CIS project management related course instructional design. It allows ERP project management instructors to move away from the discrepancy between the courses and body of knowledge. It is meant to be a generic ERP implementation conceptual model with implications for any business processes. The interrelationships of five primary sectors that are at the database security system are presented in this paper. The ERP implementation system model consists of five sectors: a) company characteristics, b) ERP implementation plan, c) communication, d) user, and e) technology management.
\end{abstract}

Index Terms - Enterprise resource planning, administrator, implementation, system model.

\section{INTRODUCTION}

Enterprise resource planning (ERP) is a cross-functional enterprise system that serves as a framework to integrate and automate many of the business processes that must be accomplished within the manufacturing, logistics, distribution, accounting, finance, and human resources functions of a business. In other words, it attempts to integrate all departments and functions across a company onto a single computer system that can serve all those different departments' particular needs. The integrated approach can have a tremendous payback if companies have well planned implementation. Many companies report significant reductions in transaction processing costs and hardware, software, and IT support staff compared to the non-integrated legacy systems that were replaced by their new ERP systems. ERP can assist in reducing cost from operation management standpoints [1]. Also, from enterprise agility viewpoints, ERP can be used in breaking down many former departmental and functional walls, which results in more flexible organizational structures, managerial responsibility, and work roles. The result is a more agile and adaptive organization and workforce that can more easily capitalize on new business opportunities.

Manuscript received December 20, 2012; revised March 12, 2013.

Carin Chuang is with the Department of Computer and Information Technology, Purdue University North Central, Westville, IN 46391 U.S.A. (e-mail: cchuang@pnc.edu).

Kuan-Chou Chen is with Department of Information Systems, Purdue University Calumet, Hammond, IN 46323 U.S.A. (e-mail: kchen@purduecal.edu).
ERP serves as the vital backbone information system of the enterprise, helping a company achieve the efficiency, agility, and responsiveness required to succeed in a dynamic business environment. However, properly implementing ERP systems is a difficult and costly process that has caused serious business loses for some companies, who underestimated the planning, development, and training that were necessary to reengineer their business processes to accommodate their new ERP systems [2].

This study will demonstrate the critical factors of ERP implementation challenges in order to identify the key components causing the failures. These key components will serve as foundation information to build a conceptual system model explores the implementation system behavior. The system model will guide the ERP decision makers and administrators as they attempt to steer the implementation clear of these obstacles. Specifically, this paper demonstrates a model of ERP implementation system based on nowadays real case study, theory and expert knowledge. The relationships in the model are designed to be simple and functional and do not necessarily represent any particular business environments. It is meant to be a generic ERP implementation system model with implications for scenario planning sequences. It allows ERP related administrators to move away from the discrepancy between the real world symptoms and simple software installation. The interrelationships of five primary sectors that are at the ERP implementation system are presented in this paper. They include a) company characteristics, b) ERP implementation plan, c) communication, d) user, and e) technology management. There are interactions within each of these sectors depicted by system loop map.

\section{LITERATURE REVIEWS}

\section{A. Systematic View Can Help Solve the Problems}

Managerial problems persist because managers continue to believe that there are such things as unilateral causation, independent and dependent variables, origins, and termination [3].

On the other hand, managerial system contains as many as 100 or more variables that are relevant and believed to be related to one another in various nonlinear fashions. The behavior of such a system is complex far beyond the capacity of intuition. Computer simulation is one of the most effective means available for supplementing the correcting human intuition [4]. The feedback structures of real problems are often so complex that the behavior they generate over time can usually be traced only by simulation [5]. 
Controlled experiments are costly and time consuming. The isolation of the effect and the evaluation of impact of any given practice within a large, complex and dynamic project environment can be exceeding difficult [6].

In systems thinking model, the effects of different assumptions and environmental factors can be tested. Unlike real systems, the effect of changing one factor can be observed while all other factors are held unchanged. Internally, the model provides complete control of the system organizational structure, its policies, and its sensitivities to various events. Externally, a wider range of circumstances can be generated than are apt to be observable in real life.

\section{B. Characteristics of Systematic View}

System dynamics is based on four premises [7].

The behavior of an organizational entity is principally caused by its structure. The structure includes not only the physical aspects, but more importantly the policies and procedures, both tangible and intangible, that dominate decision making in the organizational entity.

Managerial decision making takes place in a framework that belongs to the general class known as information feedback systems.

Our intuitive judgment is unreliable about how these systems will change with time, even when we have good knowledge of the individual parts of the system.

Thorough model experimentation is possible to fill the gap where our judgment and knowledge are weakest, by showing the way in which the known separate system parts can interact to produce unexpected and troublesome overall system results.

\section{Systematic View of ERP Project Management}

Project management is one of the most important areas of management. However it is also an area that is not well understood. Delays and cost overruns are common for projects in construction, defense, software, and other industries. Many projects suffer from the " $90 \%$ syndrome". It describes a project that reaches about $90 \%$ completion according to the original project schedule but then stalls, finally finishing after about twice the original duration has elapsed [8]. Software development often suffers from Brook's Law, which says adding manpower to a late software project makes it later [9]. Most of projects are very complex and contain multiple interacting feedback loops. Feedback refers to self-correcting and self-reinforcing side effects of decisions. For example, managers often use overtime to bring a late project back on schedule. However, if overtime remains high for an extended period, workers may become burned out which leads to lower productivity, a higher rate of errors, and increased employee turnover [10]. Thus a business decision that is expected to solve a problem actually escalates the problem. In addition, feedback loops in a complex system often interact with one another. Overtime also causes cost overrun, which may increase the pressure to reduce the project scope or to drop planned tasks just to rein in the spending. Therefore, it is fundamental to understand the dynamics of project management to improve the performance.

Traditional cost and scheduling tools such as critical path methods do not adequately account for feedback effects [10]. Human are normally error prone to feedback, nonlinearity and causality, and in controlled experiments have repeatedly shown to misperceive the feedback structure of systems much simpler than a large engineering or construction project. Though very helpful to schedule the sequence of activities in a project, tools such as Gantt charts, PERT, and critical path methods do not solve the problem. Because neither do these traditional tools account for the feedback of variables, nor do they trace dynamics intrinsically in project management. Process such as hiring and training unfold over time. There are multiple time delays in carrying out programs, in discovering and correcting errors, and in responding to unexpected changes in project scope or specifications. Thus, hiring additional workers adds to the capability of an organization in the long run. But in the short run, productivity is reduced because experienced workers must divert time from their work to train the recruits and more time is spent on communication within the organization. Only system dynamics can model such dynamic behaviors.

\section{ERP Projects Related to Project Management Control}

An ERP project is one that implements ERP software system as an organizational management information system. As any project, it has three dimensions, cost, time, and scope. The principal reason for failure is often associated with poor management of the implementation process [11]. Thus in-depth knowledge of project management will help a successful implementation of ERP system.

Though ERP system promises great advantage, it faces far more risks than a normal project. Organization and business process must be changed to adopt the new system and process. Software of all lines of business must be modified to be able to communicate with ERP system. Extensive user involvement and training are required for ERP system to be accepted by end users [12]. For a global company, it must also consider culture difference when ERP system is implemented in multiple sites. And quite often, companies do not have an in-house skill to implement an ERP system. Specialists must be hired. These risk factors that are unique to an ERP project present tremendous challenges to project managers.

\section{AN ERP IMPLEMENTATION SYSTEM MODEL}

The literature provides some guideline for a generic course development model of a Web security model. Web security features that are commonly listed under part of information security include operations systems, legal and ethical issues, network security, risk management, and technical disciplines. Some of these features are necessary for or related with other courses. For example, risk management needs to have legal and ethical discipline up front.

Based on our review of the literature and our examination of current ERP implementation problems, we propose an ERP implementation system model consists of five sectors: [13] company characteristics, [14] ERP implementation plan, [15] communication, [16] user, and [17] technology management. How these areas function together and interact with each other is shown in Fig. 1. 


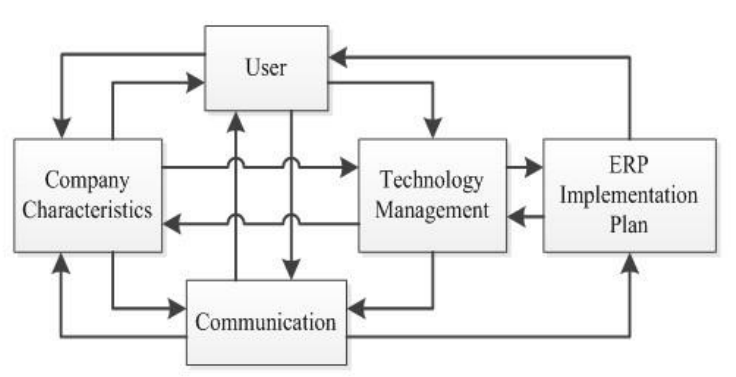

Fig. 1. An ERP implementation system model.

\section{A. Company Characteristics}

Three factors are behind the ERP implementation progress: industry characteristics, organizational structure, and company size. In this sector, we look at interrelationships between these three factors. For example, the company size will have impacts from cost/budget system to ERP investment decision. Also, organizational structure will be related to resources administration and affect the ERP control. In general, more sophisticated organization structure will have more resistance from the each segment because the resources and information sharing always have the human factors and politics involved. Industry characteristics are the key to be successful for ERP implementation. More IT related industry will have more intention to organize resources in ERP. More sensitive data related industry (e.g. accounting) would have less interest in using ERP.

\section{B. Communication}

Communication is a key implementation consideration because there are so many user groups impacted by an ERP program both internal (e.g., Stakeholders, System Operators) and external to the Company (e.g., investors). A communication strategy that includes tactical methods of disseminating ERP program information both top-down and bottom-up via diverse communication channels is an effective approach that contributes to implementation plan success [13].

\section{ERP Implementation Plan}

Business managers and IT professionals have been the major cause of ERP failures. The reason given is that these individuals underestimate the complexity of the planning, development, and training that are needed to prepare for a new ERP system that would radically change their business processes and information systems. Failure to involve affected employees in the planning and development phases and change management programs, or trying to do too much too fast in the conversion process, are also typical causes of failed ERP projects. Insufficient training in the new work tasks required by the ERP system, and failure to do enough data conversion and testing, are other causes of failure. In other cases, ERP failures are also due to over reliance by company or IT management on the claims of ERP software vendors or the assistance of prestigious consulting firms hired to lead the implementation. Identify the factors that led to the development of Enterprise Resource Planning (ERP) systems. It will assist the distinguishing characteristics of ERP software. Also, exploring the pros and cons of implementing an ERP system will enhance ongoing developments in ERP [18].

\section{User}

In non-ERP development projects, the conventional wisdom is to include users on the project team. In an ERP implementation, the parallel is to include users from across the affected functional areas. This insures that consensus is reached on requirements an also helps buy-in to occur. If the people in the different departments that will use ERP don't agree that the work methods embedded in the software are better than the ones they currently use, they will resist using the software or will want IT to change the software to match the ways they currently do things. This is where ERP projects break down [15].

ERP users are the company's employees. A company's employees are the most valuable asset to the company. Companies realize that a well-trained and experienced employee is very valuable and have begun to use the term "human capital management." Good management of employees is even more important in a large organization. Effective information systems can help manage employees [14].

\section{E. Technology Management}

In technology, ERP implementation will involve software selection, data conversation, integration, testing, software customization and data analysis. Based on Deloitte Consulting survey of 64 Fortune 500 companies, one in four admitted that they suffered a drop in performance when their ERP system went live. Performance becomes the difficulty in ERP implementation. It is very costly to have customization efforts to modify the ERP software to fit with powerful users' needs. Customizations make the software more unstable and harder to maintain when it finally does come to life. Because ERP covers so much of what a business does, a failure in the software can bring a company to a halt, literally. It is important to have implementation plan of how ERP controls the flow of information for the each department [19].

\section{Using This Study as TEACHING ToOL}

ERP project implementation is a practical profession dedicated to addressing unique needs and achieving specific goals. The successful practitioner, in any profession, must be highly motivated to address these needs successfully. Providing the opportunity for students to recognize and understand these needs and associated goals as soon as possible in the learning process, through the study of and interaction with models such as the one described in this study, is vital to their success as students and practitioners.

The following two suggestions outline general instructional principles for the ERP project implementation systems thinking model:

1) When implementing the ERP project implementation systems thinking model, the instructor should focus on the concepts of the ERP system and how to express and interrelate the project control factors that comprise this system.

2) Classroom implementation, with students playing the part of various components of the system, can be used to demonstrate the policy impacts of triple constraints (time, cost, scope) in ERP project implementation. Group 
discussion offers a more personal and dramatic way of demonstrating and learning important concepts. Group discussion also can demonstrate convincingly that prevailing environmental factors are a primary determinant in the decision-making process. Decisions regarding the best action are often so powerfully influenced by available information that intuitive decisions by different people are surprisingly similar.

\section{CONCLUSION}

Enterprise resource planning is a cross-functional enterprise system that integrates and automates many of the internal business processes of a company, particularly those within the manufacturing, logistics, distribution, accounting, finance, and human resource functions of the business. Thus, ERP serves as the vital backbone information system of the enterprise, helping a company achieve the efficiency, agility, and responsiveness required to succeed in a dynamic business environment. ERP software typically consists of integrated modules that give a company a real-time cross-functional view of its core business processes, such as production, order processing, and sales, and its resources, such as cash, raw materials, production capacity, and people. However, properly implementing ERP systems is a difficult and costly process that has caused serious business losses for some companies, who underestimated the planning, development, and training that were necessary to reengineer their business processes to accommodate their new ERP systems. However, continuing developments in ERP software, including Web-enabled modules and e-business software suites, have made ERP more flexible and user-friendly, as well as extending it outward to a company's business partners.

Training of end users is a key success factor to achieving benefits. The users must relearn the process and training is the key to getting back up-to-speed. Productivity can suffer in an implementation until uses get up-to-speed.

\section{REFERENCES}

[1] J. A. O'Brien, Management information systems, New York: Irwin/McGraw Hill, 2006.

[2] M. Olson, Managerial issues of Enterprise Resource Planning Systems, New York: McGraw-Hill, 2004.

[3] K. E. Weick, The social psychology of organization, 2nd ed. Reading, MA: Addison-Wesley Publishing Cp., Inc., 1979.

[4] E. B. Roberts, System dynamics-an introduction, in managerial applications of system dynamics, edited by E. B. Roberts, Cambridge, MA: the MIT Press, 1981.

[5] G. P. Richardson and G. L. Pugh, Introduction to system dynamics modeling and Dynamo, Cambridge, MA: the M.I.T. Press, 1981.

[6] R. L. Glass, Modern programming practices: A report from industry, Englewood Cliffs, NJ: Prentice-Hall, 1982.

[7] T. K. A. Hamid and S. E. Madnick, Software project dynamics: An integrated approach, Englewood Cliffs, NJ: Prentice Hall, Inc., 1991.

[8] D. Ford and J. Sterman, "Overcoming the 90\% syndrome: Iteration management in concurrent development projects," Concurrent Engineering: Research and Applications, vol. 11, no. 3, pp. 177-186, 2003.

[9] F. P. Jr. Brooks, The mythical man-month essays on software engineering, Anniversary Edition, Reading, MA: Addison-Wesley, pp. $25,1995$.
[10] J. D. Sterman, "System dynamics modeling for project management," Paper on World Wide Web page, Director, Systems Dynamics Group, Sloan School of Management, 1992.

[11] Y. Yusufa, A. Gunasekaranb, and M. S. Abthorpe, "Enterprise information systems project implementation: A case study of ERP in Rolls-Royce," International Journal of Production Economics, vol. 87, pp. 251-266, 2004.

[12] E. J. Umble, R. R. Haft, and M. M. Umble, "Enterprise resource planning: Implementation procedures and critical success factors," European Journal of Operational Research, vol. 146, issue 2, pp. 241-257, 2003.

[13] Enterprise Solution Competency Center. (2006). [Online]. Available: http://www.army.mil/aeioo/erp/keyic.htm

[14] Y. Jiang, "Critical success factors in ERP implementation in Finland," The Swedish School of Economics and Business Administration, Unpublished Mater Thesis, 2005.

[15] C. Koch. (2003). The ABCs of ERP. [Online]. Available: http://www.cio.com/research/erp/edit/erpbasics.html

[16] T. R. Lee, J. C. Hu, and Z. M. Lee, "Application of the system thinking approach in ERP implementation for flower chain-stores owned by a Taiwan enterprise in China," International Journal of Enterprise Network Management, vol. 1, no.1, pp. 41-61, 2006.

[17] E. Monk and B. Wagner, Concepts in enterprise resource planning, Boston: Course Technology, 2006.

[18] S. Roa, "Enterprise resource planning: Business needs and technologies," Industrial Management and Data Systems, vol. 100, no. 2, pp. 81-88, 2000.

[19] M. Sumner, "Risk factors in Enterprise-wide/ERP projects," Journal of Information Technology, vol. 15, no. 4, pp. 317-327, 2000.

Carin Chuang earned her Ph.D. in technology management at Purdue University, West Lafayette, Indiana. USA. Currently, she is an associate professor in the Department of Computer \& Information Technology at Purdue University North Central, Westville, Indiana. Dr. Chuang's primary teaching responsibilities are in database design and analysis, Internet programming, e-commerce and business implementation, and system analysis and design. Before entering academia, Dr. Chuang has been working over 15 years of professional experience as a database administrator, software developer and system analyst for three Fortune 100 companies in Chicago, Indiana and Michigan. Dr. Chuang's research interests are focused on the enterprise resource planning (ERP) implementation and evaluation, system dynamics, system simulation, distance learning and service learning. Dr. Chuang is a certified JAVA developer, SQL Server Administrator and Internet programmer. Recently, Dr. Chuang has been awarded for a Scholarship of Engagement (SOE) faculty grant from Indiana Campus Compact to design and revise her course with a community partner agency to include a service-learning component.

Kuan-Chou Chen was awarded his two Ph.D. degrees from the Michigan State University as well as an MBA degree in Management Sciences from National Cheng-Kung University at Taiwan. He has published more than 30 journal articles and 70 conference proceedings in information systems, decision support systems, data mining, instructional design, and systems thinking model. He is an active participant in several professional journals and serves on two journals reviewer boards: Journal of Management Information Systems, and International Journal of Electronically Commerce. $\mathrm{He}$ has been taught at several universities: Lansing Community College, Purdue University West Lafayette, Bowling Green State University, IVY Tech State College, and Davenport University.

$\mathrm{He}$ is department head and professor of Department of Information Systems at Purdue University Calumet. His primary teaching responsibilities are in management information systems, database management, computer programming, e-business, decision support systems, knowledge management, project management, supply chain management, and system analysis and design. Research interests are focused on the system management, network design and security, instructional design for information technology training, data mining, system dynamics, and information technology economics of information systems, network security, and applications of neural networks to network design. In his consulting career, he specialized in database design and management, information technology project evaluation and feasibility studies, web site planning and analysis, and networking planning and design. Prior to coming back academia, Dr. Chen worked as information analyst and project manager for four years. Dr. Chen received a 2005-2006 outstanding teaching award in Purdue University Calumet. Dr. Chen was nominated as a 2006, 2007, 2009 outstanding scholar award in Purdue University Calumet. 